\title{
NONEXISTENCE OF SOLUTIONS FOR SECOND-ORDER INITIAL VALUE PROBLEMS
}

\begin{abstract}
DANIEL C. BILES
Abstract. We consider nonexistence of solutions for second-order initial value problems. Two results are given: one in which the problems are singular in the time variable, and one in which the problems are singular in both the time and state variables.
\end{abstract}

Mathematics subject classification (2010): 34A12, 34A34, 34A36.

Keywords and phrases: Nonexistence of solutions, singular differential equations, second-order initial value problems.

\section{REFERENCES}

[1] R. P. Agarwal and Donal O'Regan, Singular Differential and Integral Equations with Applications, Springer, New York, 2003.

[2] AfGAn Aslanov, On the existence of a solution of a second-order singular initial value problem, Math. Methods Appl. Sci. 38, (2015), 980-990.

[3] Abdelhamid Benmezai ANd WAssila EsSERHANE, Existence of positive solutions for a singular second-order boundary value problem, J. Abstr. Differ. Equ. Appl. 3, (2012), 28-41.

[4] Abdelhamid Benmezai, Wassila Esserhane and Johnny Henderson, Nodal solutions for singular second-order boundary-value problems, Electron. J. Differential Equations 156, (2014), $39 \mathrm{p}$.

[5] Abdelhamid Benmezai, John R. Graef and Linguu Kong, Positive solutions to a two point singular boundary value problem, Differ. Equ. Appl. 3, (2011), 347-373.

[6] Pavol Brunovský, Aleš Č ERnÝ And Michael Winkler, A singular differential equation stemming from an optimal control problem in financial economics, Appl. Math. Optim. 68, (2013), 255-274.

[7] YongPeng Chen and Baoxia Jin, Positive solutions of singular second-order integral boundary value problems, J. Math. Res. Appl. 34, (2014), 337-348.

[8] He Ping Cheng, Guang Chong Yang And Wen Yong Yan, New results of nonlinear secondorder singular initial value problems, Nonlinear Funct. Anal. Appl. 10, (2005), 665-676.

[9] J. A. Cid, O. L. Pouso AND R. L. Pouso, Existence of infinitely many solutions for second-order singular initial value problems with an application to nonlinear massive gravity, Nonlinear Anal. Real World Appl. 12, (2011), 2596-2606.

[10] J. A. Cid, R. L. Pouso AND R. EnguiçA RoQue, Sharp conditions for the existence of solutions of second-order autonomous differential equations, Mediterr. J. Math. 4, (2007), 191-214.

[11] Meiqiang Feng, Xuemei Zhang and Weigao Ge, New existence theorems of positive solutions for singular boundary value problems, Electron. J. Qual. Theory Differ. Equ. 13, (2006), 9 p.

[12] Nicholas Fewster-Young ANd Christopher C. Tisdell, Existence of solutions to derivativedependent, nonlinear singular boundary value problems, Appl. Math. Lett. 28, (2014), 42-46.

[13] Petio Kelevedjiev and Nedyu Popivanov, Second-order initial value problems with singularities, Bound. Value Probl. 2014:161, 15 p.

[14] Lishan Liu, Ying Wang, Xinan Hao and Yonghong Wu, Positive solutions for nonlinear singular differential systems involving parameter on the half-line, Abstr. Appl. Anal. (2012), 20 p.

[15] YANSHENG LIU AND BAOQIANG YAN, Multiple positive solutions for a class of nonresonant singular boundary-value problems, Electron. J. Differential Equations 42 (2006), 11 p. 
[16] R. L. Pouso, Necessary and sufficient conditions for existence and uniqueness of solutions of secondorder autonomous differential equations, J. London Math. Soc. 71 (2005), 397-414.

[17] Baoqiang Yan, Donal O'Regan And Ravi P. Agarwal, Multiplicity and uniqueness results for the singular nonlocal boundary value problem involving nonlinear integral conditions, Bound. Value Probl. 2014, 22 p. 